\title{
The Impact of Campus Culture on the Satisfaction Level of Engineering Students: A Metaheuristics Approach
}

\author{
Hemaid Alsulami, ${ }^{1}$ Emad H. Abualsauod ${ }^{D},{ }^{2}$ Madani Abdu Alomar, ${ }^{3}$ Suhail H. Serbaya, \\ Asem Majed Othman, ${ }^{4}$ and Ali Rizwan $\mathbb{D}^{1}$ \\ ${ }^{1}$ Department of Industrial Engineering, Faculty of Engineering, King Abdulaziz University, Jeddah 21589, Saudi Arabia \\ ${ }^{2}$ Department of Industrial Engineering, College of Engineering, Taibah University, Madina Almonawara 41411, Saudi Arabia \\ ${ }^{3}$ Department of Industrial Engineering, Faculty of Engineering-Rabigh, King Abdulaziz University, Jeddah 21589, Saudi Arabia \\ ${ }^{4}$ Department of Industrial and Systems Engineering, College of Engineering, University of Jeddah, Jeddah 21959, Saudi Arabia
}

Correspondence should be addressed to Ali Rizwan; arkhan71@kau.edu.sa

Received 22 November 2021; Revised 26 December 2021; Accepted 29 December 2021; Published 17 January 2022

Academic Editor: Vijay Kumar

Copyright (c) 2022 Hemaid Alsulami et al. This is an open access article distributed under the Creative Commons Attribution License, which permits unrestricted use, distribution, and reproduction in any medium, provided the original work is properly cited.

\begin{abstract}
This research aims to assess the impact of campus culture on the satisfaction level of engineering students. Five latent variables, namely, respect, creativity, support, extracurricular activity, and individual responsibility, were used to examine the impact of campus culture. The data were collected with the help of an online questionnaire, which was distributed among male and female students. Subsequently, 304 responses were collected, which were analyzed using descriptive statistics, multicollinearity, and structural equation modeling (SEM) via AMOS 23 software. Internal consistency and reliability of each construct were done through Cronbach's alpha, while confirmatory factor analysis was used for the validation of results. The findings of the metaheuristics-based research indicate that the campus culture has a positive impact on the satisfaction level of students $(r=0.774$, $p<0.001)$. Improving these factors reciprocally increases the satisfaction level, besides raising the education quality. This research can provide a gateway for educational leaders in focusing their resources for the best satisfaction of their students.
\end{abstract}

\section{Introduction}

Education is the most important pillar of society and the basis for its development and stability. The student satisfaction is considered one of the prominent factors affecting the quality of education. Student's satisfaction encourages better learning outcomes and makes them better for their field of study once they graduate [1]. Good quality education provides better prospering opportunities, and the levels of satisfaction or dissatisfaction strongly affect the student's success or failure of learning. The campus environment is assumed the most critical influence and incentives to raise the level of student satisfaction and that is a goal sought by all distinguished educational institutions. Supporting students through dealing with their creative idea, increasing the level of the individual's responsibility, promoting them to participate in extracurricular activities, and respecting their culture will improve university campus culture and impact positively on student satisfaction. This study was applied to the students of engineering departments to seek their views on several aspects of teaching, assessment, and support provided by their university. The aim is to increase satisfaction, minimize dissatisfaction, and improve the factors affecting campus culture.

The academic culture of the universities mainly consists of academic outlooks, academic spirits, academic ethics, and academic environments. Shen [2] concluded the campus culture as "It is the general name of the external form of materialization in the development of university characterized by individuality, academic feature, opening, leading, variety, and creativity". Similarly, the different factors of the campus culture were studied by Han [3] which are material culture, spiritual culture, and institutional culture. The results show that the truth, goodness, and heavy morality have 
a greater significant correlation with the material culture in the campus culture; Chigo and Patriotic have a greater significant correlation with the spiritual culture; only Innovate has a greater significant correlation with the institutional culture. The department of business and law at a UK university conducted a study to measure the satisfaction of students. The quadrant analysis and SPSS were used to analyze the data, and the results of the research concluded that the most important aspects consist of teaching and learning, and the least important aspects consist of physical facilities [4]. Creativity is an essential factor in campus culture, and it can grow when there is a different culture on the campus. The creativity can be increased by making students focus on their main courses, or they will lose their intellectual focus and creative passion [5]. The parents play an important role in their educational journey. The role of parents in affecting their children's sustainability and success in the engineering field at the university level is discussed in this work [6]. The relation of group formation on the outcome of a 4-week online course for students is done [7]. A statistical study was conducted at university about extracurricular activities. The study uses the AMOS23 software to analyze the data and found that there are significant differences in the GPA of the students who participated in ECA and other nonparticipants [8]. Yang [9] published "The function and implementation strategy of campus culture activities in training talents". In this study, sports support showed a positive effect as they found that thousands of students are interested in sports, which strengthens their affiliation with the university.

Different statistical techniques are used for data validation as Julian Nasello has applied the Cronbach alpha test to validate his questionnaire [10]. The test tells you that your items measure (or not) the same concept; it is called an internal consistency measure. You need to test several psychometric properties to validate a questionnaire (e.g., content validity, construct validity, and test-retest). Alsowayigh [11] published a project about the assessment of the safety culture in Saudi airlines. He explained the importance of measuring the confidence of safety among the pilots of the company. The importance of this study is that it studies one of the types of cultures and their impact on one of the factors. This study used the AMOS 23 program, applying the statistical tools from a drawing that represents the study as a form until the results are extracted.

This study differs from the previous studies as it studies the impact of campus culture on the level of student satisfaction using a metaheuristics approach. Most of the previous research analyzed and demonstrated parts and factors of campus culture. Many studies were conducted on the level of student satisfaction in universities [12-14], but they did not study what factors influence them. The study of cultures and the analysis of their factors is a popular field, but campus culture is a new field. The statistical methods are familiar, and their examples have not been applied to the campus culture. This metaheuristics-based study investigates the effect of campus culture on the level of satisfaction and will also identify the most prominent factors among students using SPSS statistical tool and an AMOS 23 program. The results from this study will be used for the betterment of the university's performance.

\section{Materials and Methods}

2.1. Research Strategy. The survey method of research was used in this study, which is considered the most practical way to collect data from students in terms of time and cost [15]. The survey questions were designed based on five main factors measuring the campus culture including respect, creativity, support, extracurricular activities, and individual responsibility. These factors of campus culture have been selected based on the previous studies. 26 questions were included in the survey that the respondents had to answer with a 5-point Likert scale ranging from 1 (strongly disagree) to 5 (strongly agree). A proposed model was constructed to evaluate the relationships between campus culture and student satisfaction. Figure 1 illustrates the model of campus culture and student satisfaction. As we know, student satisfaction is closely linked to the quality of education; therefore, the current level of student satisfaction has also been measured based on the factors of campus culture.

The study contains five variables that affect campus culture. These factors facilitate statistical analysis to measure students' satisfaction about campus culture. A brief explanation has been introduced to obtain each factor in this study and to avoid any kind of confusion about what the intention of these factors is in Table 1.

The questionnaire was distributed to students from different engineering departments, and data were collected. Sortation is based on only two main criteria: gender and batch number. Also, to ensure accurate participant response, participation was voluntary and anonymous. Method of distribution was implemented to make the research valid and to increase the number of participants. The questionnaire was distributed among 588 male and 212 female students, and the number of participants who filled the questionnaire was 304 with a response rate of $38 \%$, set with a confidence level of $99 \%$ and margin of error of $9.3 \%$.

2.2. Analysis. The data obtained were analyzed through three stages: the first stage is a descriptive statistic, the second stage is confirmatory factor analysis (CFA), and the third stage is analyzed using the structural equation modeling (SEM). CFA and SEM were applied through AMOS 23 software.

The validation of research outcomes was through Cronbach's alpha, which calculates each variable to ensure that there is internal consistency reliability between each construct. Excel sheet and SPSS software were used to measure Cronbach's alpha for each variable. The recommended Cronbach's score was 0.70 or higher, to ensure a high level of reliability.

To determine how well the model fit the data collected, goodness-of-fit indices were used. There are much goodnessof-fit indices that can be applied but are not recommended to calculate all these indices [16]. Therefore, in this study, four indicators were used to determine the fitness including 


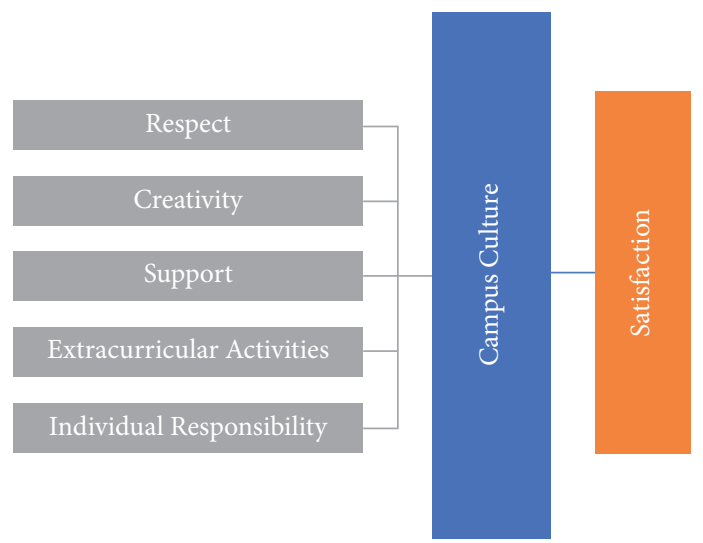

Figure 1: Proposed model of campus culture-student satisfaction.

TABLE 1: Explanation of research variables.

\begin{tabular}{|c|c|c|c|c|}
\hline & \multicolumn{2}{|c|}{ Research study variable } & \multirow{2}{*}{$\begin{array}{c}\text { Dimension } \\
\text { Diversity } \\
\text { Individuality }\end{array}$} & \multirow{2}{*}{$\begin{array}{c}\text { Explanation } \\
\text { Respect for the culture } \\
\text { Self-respect }\end{array}$} \\
\hline \multirow{5}{*}{ Exogenous variable } & 1 & Respect & & \\
\hline & 2 & Support & $\begin{array}{l}\text { Leading skills } \\
\text { Incentives }\end{array}$ & $\begin{array}{l}\text { Moral support } \\
\text { Monetary support }\end{array}$ \\
\hline & 3 & Creativity & \multicolumn{2}{|c|}{$\begin{array}{l}\text { Student creativity thinking and how university } \\
\text { deals with it }\end{array}$} \\
\hline & 4 & Extracurricular activities & \multirow{2}{*}{\multicolumn{2}{|c|}{$\begin{array}{c}\text { Extracurricular activities effect in campus culture } \\
\text { Measuring every student own reasonability about } \\
\text { the university }\end{array}$}} \\
\hline & 5 & Individual responsibility & & \\
\hline Endogenous variable & 6 & Student satisfaction & \multicolumn{2}{|c|}{$\begin{array}{c}\text { Measuring campus culture impact on student } \\
\text { satisfaction }\end{array}$} \\
\hline
\end{tabular}

chi-square statistic, comparative fit index (CFI), Tucker-Lewis index (TLI), and root mean square error of approximation (RMSEA).

2.3. Hypothesis. The hypothesis was formulated to determine statistically the question that the research answered and meet the objectives. The hypothesis tested if the campus culture has an impact on the level of satisfaction among students or not:

$\mathrm{H}_{1}$ : the campus culture has a positive effect on the satisfaction level of students

\section{Results and Discussion}

3.1. Descriptive Statistics. The survey was done using Google Forms and distributed to around 800 students, and 304 have filled the form which represents $38 \%$ of the whole population in the study. Table 2 shows the number and percentage of each gender and batch that participated in the survey.

As we can see, the number of male students is about the double number of female students, and this refers to the number of students in the male section compared to the female section. Also from the survey, it can be seen that percentage of female participation is approximately equal or greater to the male participation in most of the batches. From the above survey, it could be concluded that the female shows more excitement toward the survey rather than the male.

3.2. Multicollinearity. It is a statistical phenomenon in the analysis of multiple linear regression when two variables are related or tend to measure the same thing and thus violate one of the basic assumptions of the analysis of multiple linear regression, and this leads to unreliable and inaccurate results in the end [17]. The most effective method of ordinal data research was used which is Spearman's rho correlation matrix and to discover whether a multicollinearity problem existed between two variables. The 0.80 was used as a cutoff sign for all variables in the research. A Spearman's rho correlation matrix was applied using SPSS to all questions of campus culture indicators. The multicollinearity problem was checked between 24 questions, and the maximum value of 0.70 was noted only between the support 1 and support 4 . All correlations between the variables and campus culture indicators indicate that it is statistically significant at 0.05 . There is no multicollinearity problem because the highest correlation between any indicators did not exceed the cutoff value of 0.80 as shown in Figure 2.

3.3. Cronbach's Alpha. The validation of this study was through Cronbach's alpha, which was calculated for each variable to ensure the internal consistency reliability of each 
TABle 2: Participants with gender and batch number.

\begin{tabular}{|c|c|c|c|c|}
\hline \multirow{2}{*}{ Batch } & \multicolumn{2}{|c|}{ Male } & \multicolumn{2}{|c|}{ Female } \\
\hline & Count & $\%$ & Count & $\%$ \\
\hline$<15$ & 14 & 6.6 & 5 & 5.3 \\
\hline 15 & 20 & 9.4 & 9 & 9.6 \\
\hline 16 & 48 & 22.7 & 23 & 24.7 \\
\hline 17 & 44 & 20.8 & 17 & 18.3 \\
\hline 18 & 85 & 40.2 & 39 & 42.0 \\
\hline Total & 211 & $100 \%$ & 93 & $100 \%$ \\
\hline Mean & 42.2 & & 18.6 & \\
\hline SD & 21.253 & & 10.454 & \\
\hline
\end{tabular}

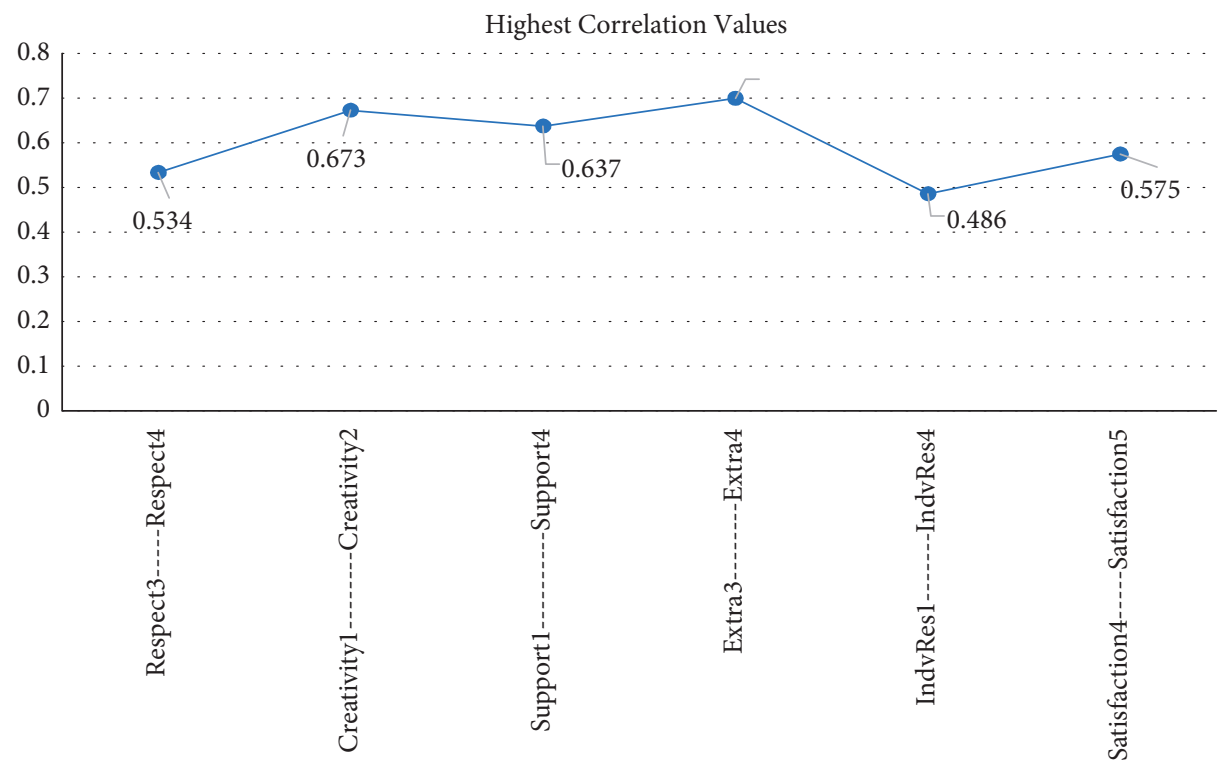

FIGURE 2: Highest correlations between indicators.

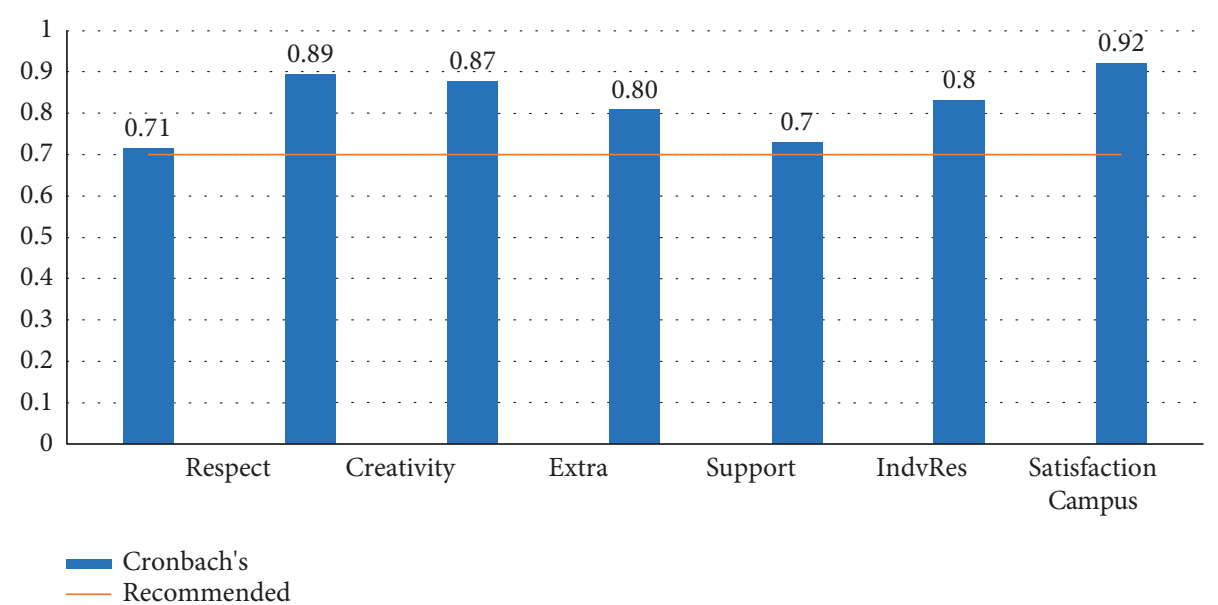

FIgure 3: Cronbach's alpha for each variable.

construct. To ensure a high level of reliability, the recommended Cronbach's alpha score was 0.70 or higher.

To measure the internal consistency of all variables, Cronbach's alpha was calculated through SPSS and excel sheet. Figure 3 shows information about Cronbach's values of all variables. It is observed that all the values are above
0.70 , which shows that all variables are reliable constructs. The highest value was noted for creativity which is about $27 \%$ larger than the specified value of 0.70 . The lowest value was noted for respect, which is 0.714 , but still, this value is above the minimum limit of 0.70 . The overall value for the campus culture was measured at 0.921 which is about $31 \%$ 


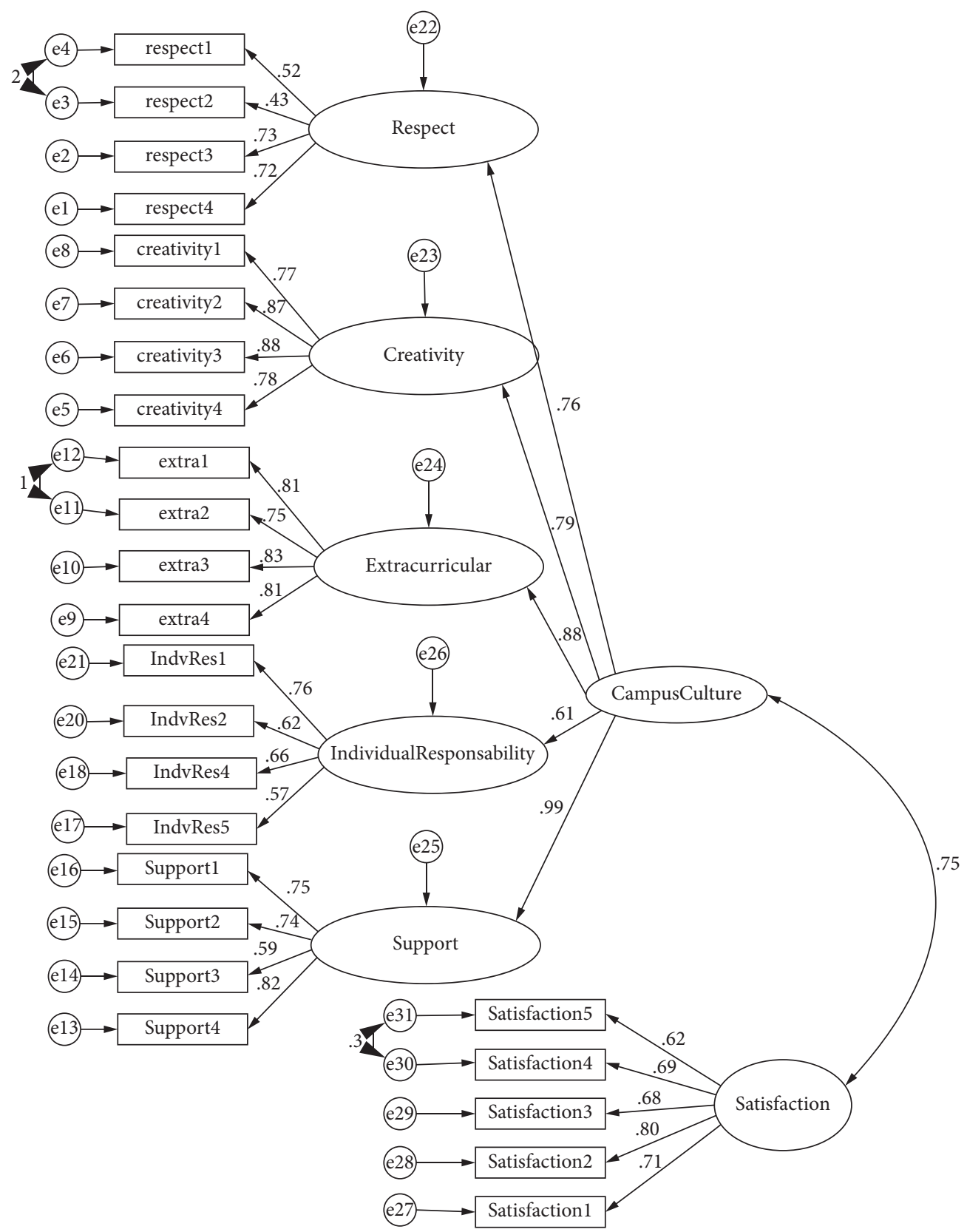

Figure 4: Initial hypothesized campus culture-satisfaction level model.

more than the minimum value of 0.70 . It shows that the whole data are reliable and have no need to improve the variables.

3.4. Confirmatory Factor Analysis (CFA). Confirmatory factor analysis was used to be sure that the model used in this research was valid. It is one of the best methods to ensure the validity of the structural equation model. One exogenous variable is campus culture, and it was identified and divided into 5 factors, as follows: respect, creativity, support, extracurricular activities, and individual responsibility. Each variable includes four or five questions that can be named as indicators. A CFA and goodness of fit were conducted for each of these factors to measure the reliability of the model via AMOS23 software. The statistical significance is checked through the critical ratio, and it should be \pm 1.96 through $p$ value which should be less than 0.05 .

Second, it is chi-square, TLI, CFI, and RMSEA that checks the model fit through the goodness-of-fit indices. The value of chi-square should be less than 4 , the value of RMSEA must be less than 0.1 , and the value of $p$-close should be greater than 0.05 [18].

3.4.1. Initial Model. The latent variables consist of four or five questions with five options for each. Initially, evaluation of factor loading and critical ratios were investigated for each indicator. All factors were above 0.5 except InvdResp 3 which was 0.35 in the initial models, which means all indicators 
TABLE 3: Initial model for the goodness-of-fit indices.

\begin{tabular}{|c|c|c|c|c|c|c|c|}
\hline \multirow{3}{*}{ Indicator } & \multirow{3}{*}{ Loading factor } & \multicolumn{5}{|c|}{ Generic model } & \multirow[b]{3}{*}{ Probability } \\
\hline & & Criticl matir & & & Fit ir & & \\
\hline & & Critical ratio & Chi. & TLI & CFI & RMSEA & \\
\hline Respect1 & 0.58 & & \multirow{4}{*}{9.21} & \multirow{4}{*}{0.807} & \multirow{4}{*}{0.936} & \multirow{4}{*}{0.157} & \multirow{4}{*}{0.01} \\
\hline Respect2 & 0.52 & 4.544 & & & & & \\
\hline Respect3 & 0.72 & 5.329 & & & & & \\
\hline Respect4 & 0.68 & 5.281 & & & & & \\
\hline Creativity1 & 0.77 & & \multirow{4}{*}{1.745} & \multirow{4}{*}{1.004} & \multirow{4}{*}{1.00} & \multirow{4}{*}{.000} & \multirow{4}{*}{.418} \\
\hline Creativity2 & 0.88 & 10.982 & & & & & \\
\hline Creativity3 & 0.88 & 11.039 & & & & & \\
\hline Creativity 4 & 0.76 & 9.484 & & & & & \\
\hline Support1 & 0.83 & & \multirow{4}{*}{4.695} & \multirow{4}{*}{0.959} & \multirow{4}{*}{0.986} & \multirow{4}{*}{0.096} & \multirow{4}{*}{0.096} \\
\hline Support2 & 0.55 & 8.322 & & & & & \\
\hline Support3 & 0.73 & 6.214 & & & & & \\
\hline Support4 & 0.77 & 8.937 & & & & & \\
\hline Extra1 & 0.83 & & \multirow{4}{*}{7.760} & \multirow{4}{*}{0.942} & \multirow{4}{*}{0.981} & \multirow{4}{*}{0.140} & \multirow{4}{*}{0.021} \\
\hline Extra2 & 0.73 & 9.484 & & & & & \\
\hline Extra3 & 0.81 & 11.061 & & & & & \\
\hline Extra4 & 0.83 & 10.763 & & & & & \\
\hline IndvResp1 & 0.59 & & \multirow{5}{*}{9.609} & \multirow{5}{*}{0.934} & \multirow{5}{*}{0.967} & \multirow{5}{*}{0.102} & \multirow{5}{*}{0.047} \\
\hline IndvResp2 & 0.65 & 5.97 & & & & & \\
\hline IndvResp3 & 0.35 & 6.30 & & & & & \\
\hline IndvResp4 & 0.60 & 5.85 & & & & & \\
\hline IndvResp5 & 0.76 & 3.68 & & & & & \\
\hline Satisfaction 1 & 0.70 & & \multirow{5}{*}{3.210} & \multirow{5}{*}{0.969} & & & \\
\hline Satisfaction2 & 0.73 & 7.970 & & & & & \\
\hline Satisfaction3 & 0.62 & 6.672 & & & 0.984 & 0.072 & 0.117 \\
\hline Satisfaction4 & 0.76 & 7.710 & & & & & \\
\hline Satisfaction5 & 0.72 & 7.426 & & & & & \\
\hline
\end{tabular}

were related to respect, creativity, support, extracurricular, individual responsibility, and satisfaction. On the other hand, all critical ratios above 1.96 and at 0.05 are significant. The maximum value for critical ratio is measured for extra3 which is 11.061. Similarly, the minimum value for the critical ratio was obtained from the IndvResp 5 which is 3.68 , but still, this value is greater than the specified limit of 1.96. An overall initial hypothesized model for the five exogenous variables and one endogenous variable is given in Figure 4.

Then, the values of fit indices were measured and are reported in Table 3. The value of chi-square must be less than 4 , and the value of RMSEA should be lower than 0.1 [19]. It can be seen from the table that the values of chi-square and RMSEA are less than the specified limits for the latent variables creativity, support, and satisfaction. Therefore, there is no need to further improve these variables $[20,21]$. In the case of latent variable respect, the value of chi-square is 9.21 which is greater than 4 , and for RMSEA, the value is 0.157 which is greater than the value of 0.1 so this latent variable needs to be improved. Similarly, the values of chi-square and RMSEA for the latent variables extracurricular and individual responsibility are also larger than the specified minimum limits. In conclusion, there is a strong need to improve the variables respect, extracurricular, and individual responsibility to get the appropriate results [22, 23].

3.4.2. Revised Model. To improve the fit model by keeping all fit indices inside the appropriate limit, the standardized residual matrix was used to define the standardized variations between the proposed function-based covariance and the observed one determined by the data obtained. The appropriate standardized residual values must also not exceed 1.96 or 2.85 . By using the standardized residual matrix, regarding the covariance term, the IndvResp2 indicator was deleted because it was out of the acceptable limit. After adding the needed covariance relation, the revised model was built. The revised model is shown in Figure 5.

AMOS 23 software has been used to improve the model fit by the indices of modifications. Modification index identifies the large error term between two indicators to correlate them resulting in a decrease in the value of chisquare. A complete revised fitness model has been given in Table 4. The indicator IndvResp 3 has been removed from the model to get better results. The value of chi-square for the latent variable was reduced from 9.21 to 2.46 which is under the acceptable limits. Similarly, the values of extracurricular and IndvResp were reduced from 7.760 to 0.399 and 9.609 to 0.709 , respectively. The values of TLI, CFI, and RMSEA are also within acceptable limits.

3.5. Structural Equation Modeling (SEM). After testing, verification, and validating the relationship among research variables, a structural equation model was built to test the hypothesis and to know the effect and the relationship between campus culture and student satisfaction. To provide a scale score for each measurement model, a composite variable function was imputed by using AMOS 23 which 


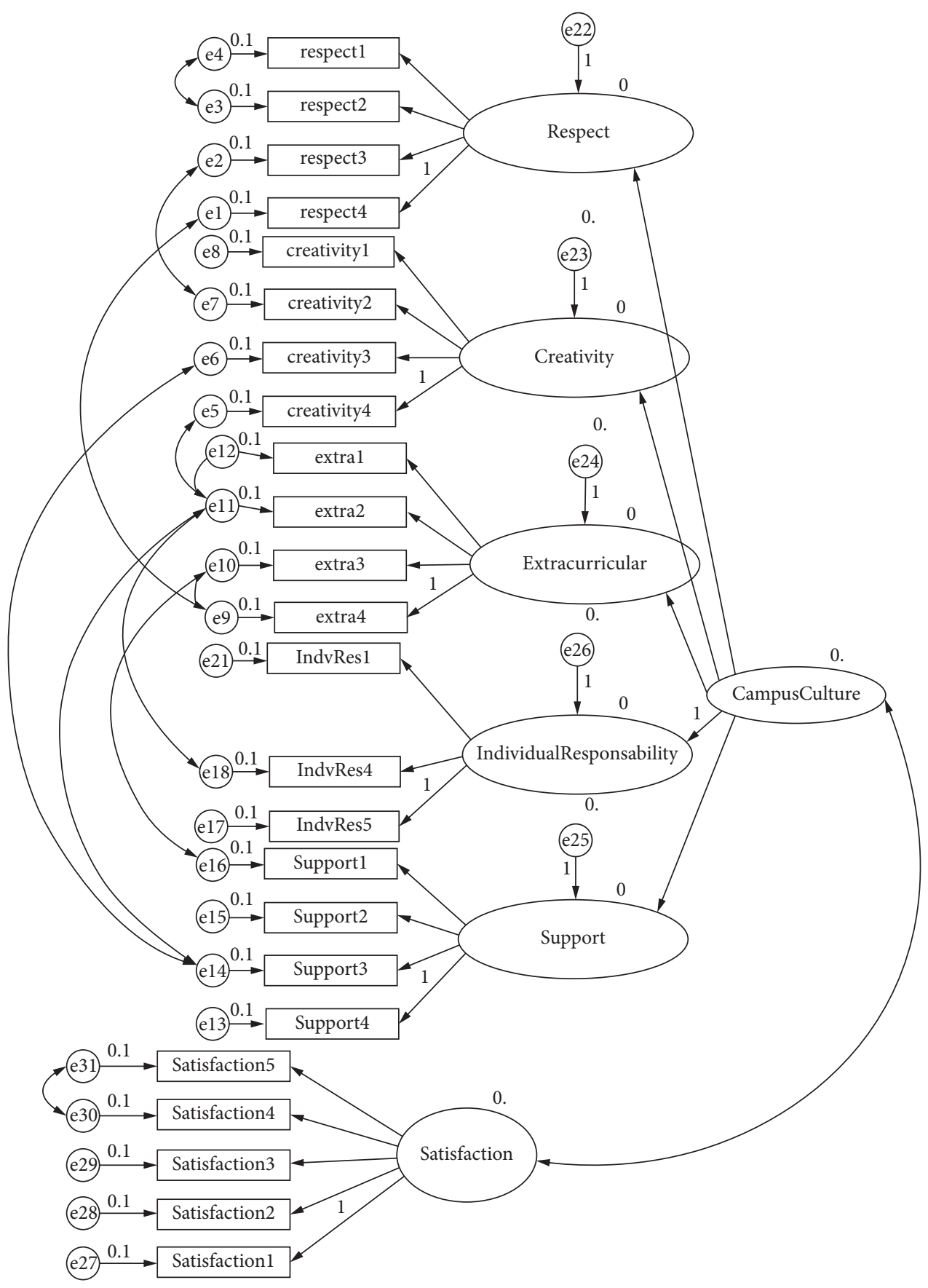

FIgURE 5: Revised campus culture-satisfaction level model.

provides a better model fit. SEM is used to measure the effect of control variables on the exogenous variables. All exogenous variables in the research fall under the campus culture which is included in the structural equation model. SEM is consisting of one variable only which is campus culture which includes six variables (respect, creativity, support, extracurricular activities, individual responsibility, and satisfaction). The control variables were included which are gender and batch number to make the study more comprehensive. It was deduced that the batch number and gender do not affect the level of satisfaction at the campus. It is the campus culture that directly affects the satisfaction level of students. Among all factors, those are very important which are linked to the teaching and learning abilities of the student. From SEM, it was concluded that the campus culture has a strong relationship with the satisfaction level. Table 5 shows that gender and batch number are not statistically significant at 0.05 , so they do not have a significant effect on satisfaction level.

The correlation between the campus culture and satisfaction variable is shown in Table 6 . The correlation was $r=0.774 \quad(p<0.001)$, which shows the significant positive correlation between the campus culture and the satisfaction of the student. 
TABLE 4: Revised models for the goodness-of-fit indices.

\begin{tabular}{|c|c|c|c|c|c|c|c|}
\hline \multirow{3}{*}{ Indicator } & \multirow{3}{*}{ Loading factor } & \multicolumn{5}{|c|}{ Revised model } & \multirow[b]{3}{*}{ Probability } \\
\hline & & Critical ratio & & & Fit it & & \\
\hline & & Critical ratio & Chi. & TLI & CFI & RMSEA & \\
\hline Respect1 & 0.52 & & \multirow{4}{*}{2.46} & \multirow{4}{*}{0.922} & \multirow{4}{*}{0.987} & \multirow{4}{*}{0.100} & \multirow{4}{*}{0.117} \\
\hline Respect2 & 0.45 & 9.823 & & & & & \\
\hline Respect3 & 0.77 & 10.191 & & & & & \\
\hline Respect 4 & 0.69 & 8.726 & & & & & \\
\hline Extra1 & 0.78 & & \multirow{4}{*}{0.399} & \multirow{4}{*}{1.012} & \multirow{4}{*}{1.00} & \multirow{4}{*}{0.000} & \multirow{4}{*}{0.527} \\
\hline Extra2 & 0.68 & 9.678 & & & & & \\
\hline Extra3 & 0.83 & 10.235 & & & & & \\
\hline Extra4 & 0.86 & 10.074 & & & & & \\
\hline IndResp1 & 0.77 & & \multirow{3}{*}{0.709} & \multirow{3}{*}{1.032} & \multirow{3}{*}{1.00} & \multirow{3}{*}{0.001} & \multirow{3}{*}{0.702} \\
\hline IndResp4 & 0.67 & 6.26 & & & & & \\
\hline IndResp5 & 0.57 & 5.65 & & & & & \\
\hline
\end{tabular}

TABle 5: Parameter estimates for campus culture-satisfaction model.

\begin{tabular}{lcccccc}
\hline & & & Estimate & SE & CR & $p$ \\
\hline Satisfaction & $<---$ & Gender & -0.048 & 0.075 & -0.638 & 0.523 \\
Satisfaction & $<---$ & Batch & -0.081 & 0.029 & -2.788 & 0.005 \\
\hline
\end{tabular}

TABLE 6: Correlation between campus culture and satisfaction level.

\begin{tabular}{lcccc}
\hline & M & SD & 1 & 2 \\
\hline Campus culture & 3.40 & 0.86 & $<0.921>$ & \\
Satisfaction & 3.25 & 0.67 & 0.774 & $<0.830>$ \\
\hline
\end{tabular}

There is one main hypothesis that tests the impact of campus culture on the satisfaction level which is the main objective of this research. At this step, the hypothesis was tested. The hypothesis was as follows:

The hypothesis was accepted because of the significant correlation of the campus culture with the satisfaction level of students $(r=0.774, p<0.001)$. So, the campus culture has a positive effect on the satisfaction level.

\section{Conclusions}

The tested hypothesis of this research was the campus has a positive effect on the satisfaction level. The campus culture model was designed with five latent variables which are respect, creativity, extracurricular activities, individual responsibility, and support. The findings of this metaheuristics-based research show that the campus culture has a positive impact on the satisfaction level of students $(r=0.774 ; p<0.001)$. So, the management of the university should make effort on improving the whole latent factors by increasing the respect of the diversity of religions and cultures. The university should work on rising and supporting creativity and giving the student the opportunity of innovation effect that improves the campus culture. Improving the support either financially or morally, the extracurricular activities, and individual responsibility also have an impact on the campus culture on its way to improve the campus culture.
To finalize this research, the survey was circulated to around 800 students from the engineering departments and different batches. The sample size of the research was 304 with $38 \%$ of the total population. The analysis starts with the confirmatory factor analysis which is used to validate the factors. This analysis studies each factor one by one than overall construct. Furthermore, the hypothesis was tested by structural equation modeling.

The population of this research was from engineering departments, and to make the research more general and bigger, the advice was to apply the approach to the whole university. To raise the level of accuracy, the sample size should be bigger, recommended to get as big as possible sample size. More questions for every variable can make it easy to apply the analysis, but be careful as the survey can make the student bored and leave the survey blank. The data can be more accurate if it is filled manually by interviewing the students.

\section{Data Availability}

The data used to support the findings of this study are available from the corresponding author upon request.

\section{Conflicts of Interest}

The authors declare that there are no conflicts of interest regarding the publication of this study.

\section{References}

[1] A. Rizwan, M. S. Alvi, and M. M. Hammouda, "Analysis of factors affecting the satisfaction levels of engineering students," International Journal of Engineering Education, vol. 24, no. 4, pp. 811-816, 2008.

[2] X. Shen and X. Tian, "Academic culture and campus culture of universities," Higher Education Studies, vol. 2, no. 2, pp. 61-65, 2012.

[3] L. Han, "Research on campus culture construction based on university's core value," 2020, http://www.doc88.com/p9893540714578.html.

[4] J. Douglas, A. Douglas, and B. Barnes, "Measuring student satisfaction at a UK university," Quality Assurance in Education, vol. 14, no. 3, pp. 251-267, 2006. 
[5] Association of American Colleges \& Universities, "Taking the measure of the creative campus," 2020, https://www.aacu.org/ publications-research/periodicals/taking-measure-creativecampus.

[6] D. Cho and J. Cho, "Influence of confucian culture and parental satisfaction with engineering majors on academic performance in engineering education," Journal of Professional Issues in Engineering Education and Practice, vol. 145, no. 3, Article ID 05019003, 2019.

[7] A. Müller, H. Bellhäuser, J. Konert, and R. Röpke, "Effects of group formation on student satisfaction and performance: a field experiment," in Small Group ResearchSAGE Publications, Thousand Oaks, CA, USA, 2021.

[8] Academicjournalsorg, "Academic journals - journals," 2020, http://www.academicjournals.org/RR.

[9] L. Yang, "The function and implementation strategy of campus culture activities in training talents," Open Journal of Social Sciences, vol. 02, no. 5, pp. 1-4, 2014.

[10] M. Heo, N. Kim, and M. S. Faith, "Statistical power as a function of cronbach alpha of instrument questionnaire items," BMC Medical Research Methodology, vol. 15, no. 1, p. 86, 2015.

[11] M. Alsowayigh, Assessing Safety Culture Among Pilots in Saudi Airlines: A Quantitative Study Approach, University of Central Florida, Orlando, FL, USA, 2014.

[12] A. Rizwan, M. S. Ratput, and M. S. I. Alvi, "Analysis of factors affecting the stress level of female engineering students," Global Journal of Human-Social Science, vol. 12, 2012.

[13] A. Rizwan, M. Choudhary, M. Jahanzaib, and A. Ammar, "Analysis of factors affecting the stress level of engineering students from remote areas," International Journal of Engineering Education, vol. 29, no. 4, pp. 926-932, 2013.

[14] A. Fakhar, M. Jahanzaib, M. H. Sarfraz, M. Shafiq, and A. Rizwan, "Investigating the impact of emotional intelligence on academic performance of engineering students: an exploratory study in Pakistan," The Nucleus, vol. 56, no. 3, pp. 105-111, 2020.

[15] Qualtrics, "How to determine the correct survey sample size," 2020, https:/www.qualtrics.com/experience-management/ research/determine-sample-size/.

[16] D. Hooper, J. Coughlan, and M. R. Mullen, "Structural equation modelling: guidelines for determining model fit," Electronic Journal of Business Research Methods, vol. 6, no. 1, pp. 53-59, 2008.

[17] Methods.sagepub.com, "Multicollinearity - SAGE research methods," 2020, https://methods.sagepub.com/reference/thesage-encyclopedia-of-communication-research-methods/ i9142.xml.

[18] L. t. Hu and P. M. Bentler, "Cutoff criteria for fit indexes in covariance structure analysis: conventional criteria versus new alternatives," Structural Equation Modeling: A Multidisciplinary Journal, vol. 6, no. 1, pp. 1-55, 1999.

[19] R. S. Landis, D. J. Beal, and P. E. Tesluk, "A comparison of approaches to forming composite measures in structural equation models," Organizational Research Methods, vol. 3, no. 2, pp. 186-207, 2000.

[20] A. Kumar, V. Jagota, R. Q. Shawl et al., "Wire EDM process parameter optimization for D2 steel," Materials Today: Proceedings, vol. 37, no. 2, pp. 2478-2482, 2021.

[21] O. Taylan, A. Rizwan, and H. Parsaei, "Optimization of engineering student learning and assessment by cognitive methods," in Engineering Education Letters Hamad bin Khalifa University Press (HBKU Press), Doha, Qatar, 2017.
[22] B. Wang, X. Yao, Y. Jiang, C. Sun, and M. Shabaz, "Design of a real-time monitoring system for smoke and dust in thermal power plants based on improved genetic algorithm," Journal of Healthcare Engineering, vol. 2021, Article ID 7212567, 10 pages, 2021.

[23] S. Deshmukh, K. T. Rao, and M. Shabaz, "Collaborative learning based straggler prevention in large-scale distributed computing framework," Security and Communication Networks, vol. 2021, Article ID 8340925, 9 pages, 2021. 